\title{
Habitat-based spatial and temporal variability in life history characteristics of female common dolphins Delphinus delphis in the eastern tropical Pacific
}

\author{
Kerri Danil*, Susan J. Chivers \\ Southwest Fisheries Science Center, NOAA Fisheries, 8604 La Jolla Shores Dr., La Jolla, California 92037, USA
}

\begin{abstract}
Spatial and temporal variability in mean age, breeding season and mean body length were examined for female short-beaked common dolphins Delphinus delphis in the eastern tropical Pacific (ETP). Specimens were obtained from central stock $D$. delphis incidentally killed in the tuna purse-seine fishery between 1973 and 1993. To examine spatial variability in life history parameters, oceanographic variables were used to characterize 2 primary habitats within the range of central stock animals: the Costa Rica Dome (CRD) and the surrounding areas of the CRD. Mean age of mature females did not vary through time or between habitats, and calving occurred throughout the year in both habitats. However, mean body length of D. delphis sampled 'on' the CRD was $10 \mathrm{~cm}$ shorter than those sampled 'off' the CRD during the years 1973-1974 but was not significantly different between the 2 habitats in the years 1988-1989. The difference between spatial groups in 1973-1974 is likely attributed to animals moving within the region in response to changes in their environment. That is, animal size and location is consistent with southern stock D. delphis moving into the higher quality habitat of the CRD area during the strong El Niño of 1972-1973 when preferred habitat was likely reduced in the area that the southern stock inhabits. Our evidence of animal movement suggests animals cross stock boundaries during periods of significant environmental change. This result has implications for development and implementation of management plans and estimation of life history parameters for $D$. delphis inhabiting the ETP.
\end{abstract}

KEY WORDS: Common dolphin $\cdot$ Delphinus delphis $\cdot$ Oceanography $\cdot$ Population dynamics $\cdot$ Costa Rica Dome $\cdot$ Life history $\cdot$ Eastern tropical Pacific $\cdot$ El Niño

\section{INTRODUCTION}

In the eastern tropical Pacific (ETP), 3 stocks of Delphinus delphis are recognized for management purposes: northern, central, and southern (Fig. 1) (Perrin et al. 1985, Dizon et al. 1994). These stocks were defined by hiatuses in distribution, differences in asymptotic length of adult animals, and differences in breeding seasonality. Incidental mortality of $D$. delphis occurs in the ETP yellowfin tuna purse-seine fishery and stock designations are used to ascertain the impact of the fishery on these populations. We focused our analyses on females from the central stock (which we will refer to as central $D$. delphis), for which the greatest number of biological samples were available.

Central Delphinus delphis inhabit a large area within the ETP that extends from near shore to thousands of miles offshore. Concentrations of D. delphis are found here in upwelling modified regions, with cool surface temperature and a shallow, weak thermocline (Fiedler \& Reilly 1994). The primary upwelling modified region that dominates the water they inhabit is the Costa Rica Dome (CRD) (Fig. 2). This thermocline dome has a distinctly higher plankton biomass than surrounding tropical waters and changes seasonally in structure and location (Fiedler 2002a). 


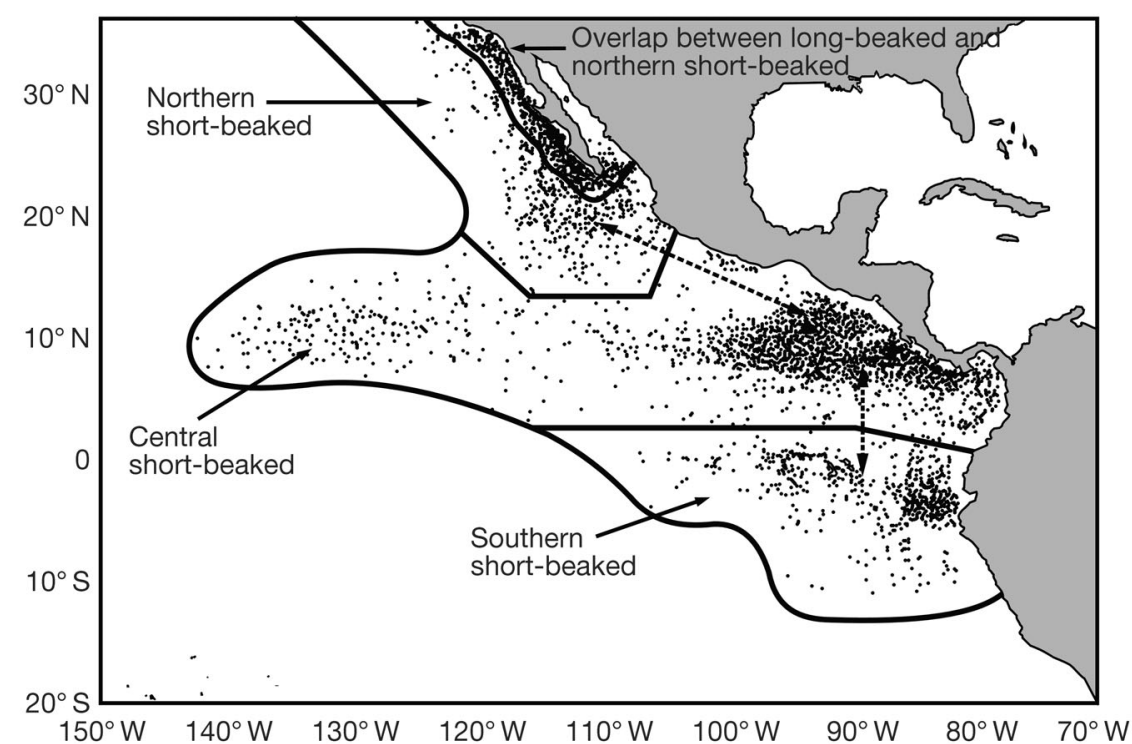

Fig. 1. Delphinus delphis. Distribution and boundaries of stocks recognized in the eastern tropical Pacific (Dizon et al. 1994). Dashed arrows indicate relative distance between the northern and southern stocks and Group B of the central stock

Although D. delphis habitat quality is highest at the CRD (Fiedler \& Reilly 1994), animals live in surrounding areas as well. Geographic distance and variation between upwelling modified habitats within this region could potentially create conditions that result in fine scale population structure that is not currently recognized but may be evident as differences in life history parameters.

Life history parameters have been shown to vary between neighboring stocks of other delphinids in the ETP (Barlow 1985, Hohn \& Hammond 1985, Perrin et al. 1985, Chivers \& Myrick 1993). For example, eastern spinner dolphins, Stenella longirostris orientalis and northern whitebelly spinner dolphins (a form of $S$. longirostris in the ETP) were found to vary in body length, breeding seasonality, and ovulation rates (Perrin et al. 1985), whereas northern and southern stocks of the pantropical spotted dolphins, Stenella attenuata, were found to differ in body length, average length at attainment of sexual maturity, proportion pregnant (Barlow 1985), and the average age at attainment of sexual maturity (Chivers \& Myrick 1993). However, interpretation of these differences is not straightforward because these populations experienced varying degrees of mortality in the yellowfin tuna purseseine fishery and may be exhibiting not only inherent population differences but also varying degrees of density-dependent responses.

Integrating both spatial and temporal analyses of life history parameters together may aid in interpreting and hypothesizing causes of observed results. However, these 2 elements have not been fully integrated in the past. Temporal trends in reproductive parameters have been examined separately for northern and southern offshore Stenella attenuata, S. longirostris orientalis and whitebelly spinner dolphins, and central Delphinus delphis (Barlow 1985, Hohn \& Hammond 1985, Chivers \& Myrick 1993, Chivers \& DeMaster 1994). These studies focused on detecting densitydependent responses and sampling biases related to the tuna purse-seine fishery. Chivers \& Myrick (1993) did not observe predicted density-dependent responses and suggested that they might not have been detected due to biological differences between subpopulations or environmental periodicity. However, these hypotheses were not tested.

This study explores differences between potential subpopulations within central Delphinus delphis and the environment they live in, over time. A priori groups of central $D$. delphis are defined based on oceanographic variables and distance from shore. Further refinement of these groups is based on a potential habitat barrier. Using these groups, mature female body length, age, and calving season are used as proxies to determine whether oceanography may be driving fine scale population structure and whether these life history parameters have changed over

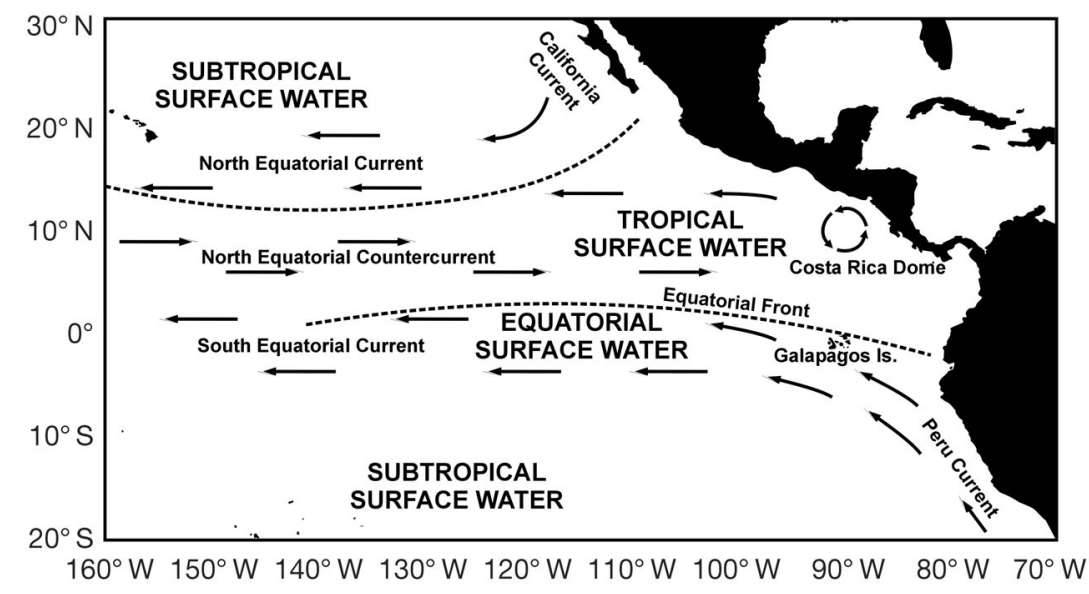

Fig. 2. Surface circulation and water masses of the eastern tropical Pacific (after Reilly \& Fiedler 1994) 
time. The impetus of this study was to explore variability in life history parameters to ascertain whether additional central $D$. delphis data may need to be stratified to account for additional population structure before embarking on an extensive life history study of this population.

\section{METHODS}

Sample collection and processing. Scientific observers from the National Marine Fisheries Service and the Inter-American Tropical Tuna Commission collected field and biological data from dolphins incidentally killed in the tuna purse seine fishery between 1973 and 1993. Body length (to the nearest centimeter), collection date, and collection location were recorded for 878 female Delphinus delphis used in this study. Body length was measured from the tip of the rostrum to the fluke notch, which is the standard measurement of total body length as defined in Norris (1961) for cetaceans. Teeth were collected from the left lower jaw at midlength and ages were estimated by counting growth layer groups in the tooth dentine (Myrick et al. 1983, Hohn et al. 1989). Two readers aged each tooth 3 times, with at least a week in between readings and without knowledge of available biological data for the specimen (e.g. body length, state of sexual maturity or reproductive condition). The mean age of both readers' 3 readings was used as the final estimate of age for the specimen.

Defining a priori groups. Oceanographic parameters and distance from shore were examined as variables to define a priori spatial groupings within central Delphinus delphis. Mean thermocline (THERM) and $20^{\circ} \mathrm{C}$ isotherm depth (Z20), sea surface temperature (SST), and surface chlorophyll concentration (CHL) were extracted by Fiedler \& Talley (2006) from the World Ocean Database. Data files from 1950 through those updated as of 30 August 2003 were used. Data collected throughout this time period were used to provide the best characterization of the oceanographic features for the area that are robust to decadal and inter-annual oscillations. The $20^{\circ} \mathrm{C}$ isotherm has been used as an index of thermocline depth in the tropics (Hansen \& Herman 1988, Kessler 1990) and has been used in conjunction with other oceanographic variables to characterize D. delphis habitat in the ETP (Reilly 1990, Reilly \& Fiedler 1994, Reilly et al. 2002). Although it is only an approximation, we have used the $20^{\circ} \mathrm{C}$ isotherm depth as a comparison and complement to actual thermocline depth, defined as the depth at which the greatest temperature change occurs, because of its historical significance. Oceanographic variables were averaged within $1^{\circ}$ map blocks and associated with the sampling locations of individual dolphins. Distance from shore (DIST) was also used as a possible discriminating variable because several studies have shown that morphometric differences exist between some offshore and inshore populations of delphinids (Walker 1981, Douglas et al. 1984, Perrin et al. 1985). Square root transformations of THERM and DIST, and a log transformation of CHL were performed to improve the normality of their distributions.

The relationship of oceanographic variables and distance from shore to body length of mature females and to each other was examined using a Spearman rank correlation test to determine which variables to include in the principal component analysis (PCA). The variables Z20, VTHERM, and SST were used in a PCA as descriptors of the habitat. These variables were used because the quality of ordination in a PCA is dependent on the colinearity of variables. Although CHL has been used in previous habitat analyses (Reilly \& Fiedler 1994, Reilly et al. 2002), it was not used in this PCA because (1) it was not correlated with body length $(p=0.3690)$ and (2) it was negatively correlated with all other oceanographic variables. A negative correlation between variables would have caused the PCA to contribute more loading to this difference rather than to the covariation of the other variables. DIST was also excluded from the PCA because it was not correlated with body length $(p=0.5329)$. The standardized score from the PCA (Table 1) was used in a $k$-means cluster analysis of collected samples.

A 2-group $k$-means cluster analysis was used to separate female central Delphinus delphis into groups based on habitat differences reflected by the PCA scores described above. These results defined the a priori groups for analyses of life history parameters.

Temporal and spatial comparisons. Sample frequencies for each a priori group were examined to determine whether sampling biases existed over time and/or season. Assignment to season was based on the

Table 1. Results of PCA. Component loadings and percent total variance values indicate that data structure was effectively summarized by all variables used

\begin{tabular}{|lcc|}
\hline Variable & Eigenvectors & Component loadings \\
\hline Z20 & 0.587 & 0.962 \\
VTHERM & 0.585 & 0.957 \\
SST & 0.560 & 0.916 \\
Latent roots (Eigenvalues) & \\
1 & 2 & 3 \\
2.680 & 0.234 & 0.086 \\
Percent of total variance explained: 89.341 \\
\hline
\end{tabular}


phases of the CRD. The following stages of the CRD (Fiedler 2002a) were used to define 'seasons' for our analysis: (1) coastal shoaling (FebruaryApril), (2) separation from the coast (May-June), (3) countercurrent thermocline ridging/intensification and expansion to the west (July-November), and (4) deepening (DecemberJanuary).

Most of the samples used in this study were collected between 1973 and 1979, with another peak in sampling in 1988 and 1989 (Fig. 3). This bias made comparison across all years inappropriate. Therefore, an 'early' (1973-1974) and a 'late' (1988-1989) time period were selected for comparison. These time periods were selected based on their large sample sizes and similarity in distribution of samples across habitat groups and sampling season. To reduce the potential of animal movement due to season, only samples collected during the same season (coastal shoaling phase) were compared.

Mean body length and age of sexually mature females was compared between habitat groups and time periods, using a 2-way ANOVA. Seasonality in female reproduction was examined using Kuiper's modification of Kolmogorov's test (Batschelet 1965) on birth dates for animals estimated to be less than $1 \mathrm{yr}$ old (Danil 2004). Birth dates were back-calculated using length at birth, growth rate during the first year, and date of capture (Danil 2004). Due to limited sample sizes, a comparison of seasonality in reproduction between time periods was not possible.

\section{RESULTS}

\section{A priori groups}

The variables Z20 $(p=0.0066)$, THERM $(p=0.0014)$, and SST $(p<0.0001)$ were all significantly correlated to mean body length of mature females, as well as being correlated with each other (Table 2). Component loadings indicate that in descending order, Z20, VTHERM, and SST contributed significantly (Tabachnik \& Fidell 1989) to the principal component structure (Table 1). The high total variance explained $(89.341 \%)$ indicates that the data structure was effectively summarized in a few dimensions.

The 2-group $k$-means cluster analysis identifies 2 oceanographic habitats that correspond to being 'on' and 'off' the CRD (Fig. 4), which is a distinctive ocea- nographic feature within the range of central Delphinus delphis. If animal movements are limited by a preference for these different habitats, the CRD, which covers an area of approximately 300 to $500 \mathrm{~km}$ in diameter (Fiedler 2002a), may act as a barrier. Habitat barriers limiting gene flow within a species have been documented in wide-ranging mammals (Geffen et al. 2004, McRae et al. 2005, Natoli et al. 2005). Therefore, we designated the similar habitats on either side of the dome as separate a posteriori groups, creating 3 groups for the spatial analysis identified as A, B, and C (Fig. 4). Groups $A$ and $C$ are considered 'off' the CRD

Table 2. Spearman rank correlations of oceanographic variables, distance from shore, and mean body length of mature females. $\mathrm{Z} 20=20^{\circ} \mathrm{C}$ isotherm depth, SST = sea surface temperature, LOGCHL = log (chlorophyll conc.), DIST $=$ distance from shore

\begin{tabular}{|llrr|}
\hline Variable & By variable & Spearman $\rho$ & Prob $>|\rho|$ \\
\hline Z20 & TOTLENGTH & 0.1266 & 0.0066 \\
SST & TOTLENGTH & 0.2100 & $<0.0001$ \\
SST & Z20 & 0.7577 & $<0.0001$ \\
LOGCHL & TOTLENGTH & 0.0420 & 0.3690 \\
LOGCHL & Z20 & -0.4181 & $<0.0001$ \\
LOGCHL & SST & -0.0712 & 0.1279 \\
VDIST & TOTLENGTH & -0.0292 & 0.5329 \\
VDIST & Z20 & -0.4219 & $<0.0001$ \\
VDIST & SST & -0.0888 & 0.0572 \\
VDIST & LOGCHLOR & 0.2546 & $<0.0001$ \\
VTHERM & TOTLENGTH & 0.1485 & 0.0014 \\
VTHERM & Z20 & 0.9169 & $<0.0001$ \\
VTHERM & SST & 0.8150 & $<0.0001$ \\
VTHERM & LOGCHLOR & -0.2360 & $<0.0001$ \\
VTHERM & VDIST & -0.1033 & 0.0269 \\
\hline
\end{tabular}




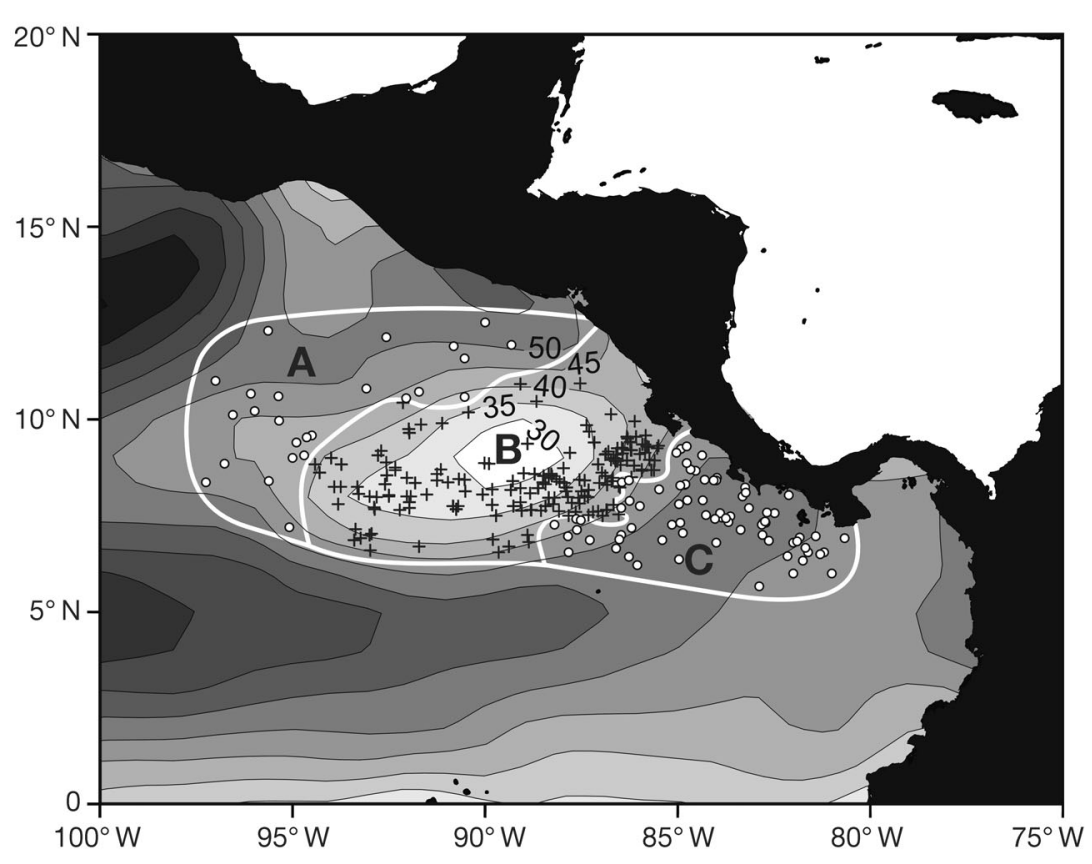

Fig. 4. Delphinus delphis. Separation of central females based on 2-group $k$ means cluster analyses. Symbols represent a priori groups based on $k$-means cluster analyses $(+=$ 'on' CRD, $O=$ 'off' CRD) and outlined areas represent $a$ posteriori groups defined by cluster analyses and the potential for the CRD to act as a habitat barrier. Contours represent $20^{\circ} \mathrm{C}$ isotherm depth (m)

differences $(p<0.05)$ in mean body length for Group B between time periods and between Groups B and C during 1973-1974. Examination of the interaction plot (Fig. 5) indicates that the mean body length of Group B was 10 $\mathrm{cm}$ shorter than $\mathrm{C}$ in the early years and that population $\mathrm{B}$ increased in length over time while Group C did not, leading to undetectable differences between the 2 groups in the later years.

Mean age of mature females did not vary by time or space. Results of 2-way ANOVA indicated that there was no significant difference between time periods $\left(F_{1,79}=2.5875, \mathrm{p}=0.1119\right)$, groups $\left(F_{1,79}=0.3499, \mathrm{p}=0.5559\right)$, or interactions between group and time $\left(F_{1,79}\right.$ $=1.6863, \mathrm{p}=0.1980)$. Back-calculated birth dates were not significantly different from a uniform distribution for both Groups B ( $\mathrm{K}=0.75, \mathrm{p}>0.10)$ and $\mathrm{C}(\mathrm{K}=0.30, \mathrm{p}>0.10)$, indicating no difference in seasonality of female reproduction (Fig. 6).

To determine whether fine scale spatial differences in sampling could be

habitat and represent a northern and southern group of central D. delphis, respectively. Group B is 'on' the CRD habitat.

A shallower thermocline depth, lower SST, and higher chlorophyll concentration characterize the habitat of Group B, which is centered on the CRD compared to Groups A and C (Table 3). Comparatively, Group A extends farthest from shore, on average, followed by Group B and then Group C.

\section{Temporal and spatial comparisons}

Samples from Group A were largely collected from 1973-1975, and thus once data were limited to 2 time periods, Group A sample sizes were too small to include in the temporal analyses. Thus, temporal variability was only examined for Groups B and C.

Mean body length of mature females varied both spatially and temporally. Results of 2-way ANOVA shows a significant difference between time periods $\left(F_{1,114}=9.619, \mathrm{p}=0.0024\right)$ and groups $\left(F_{1,114}=13.093, \mathrm{p}=0.0004\right)$, with interaction effects $\left(F_{1,114}=19.034\right.$, $\mathrm{p}<0.0001)$. The Tukey Multiple Comparison Test demonstrated significant driving the observed body length differences in Group B, sampling location maps for this group were examined. Early year (1973-1974) specimens were all collected from a limited area in the southeastern range of Group B, whereas specimens in the later years (1988-1989) were collected throughout the area (Fig. 7 ). To determine whether differences in mean body length may be due to sampling a previously undiscovered stock rather than to a change through time, mean body length of mature females for all years other than early and late was compared between those in the southeast portion and those inhabiting the rest of the CRD (Fig. 7). There was no significant difference ( $t$ test: $t_{173}=-1.440, \mathrm{p}=0.1515$ ) between these 2 groups, and therefore we concluded that the observed temporal length differences in Group B were unlikely due to the existence of a regionally isolated stock.

Table 3. Mean values of variables associated with habitat groups. Groups A and $\mathrm{C}$ represent areas 'off' the dome whereas Group B represents the 'on' dome habitat

\begin{tabular}{|lccccc|}
\hline Group & $\begin{array}{c}\text { Thermocline } \\
\text { depth }(\mathrm{m})\end{array}$ & $\begin{array}{c}20^{\circ} \mathrm{C} \text { isotherm } \\
\text { depth }(\mathrm{m})\end{array}$ & $\begin{array}{c}\text { Chlorophyll } \\
\left(\mathrm{mg} \mathrm{m}^{-3}\right)\end{array}$ & $\begin{array}{c}\text { SST } \\
\left({ }^{\circ} \mathrm{C}\right)\end{array}$ & $\begin{array}{c}\text { Distance from } \\
\text { shore (n miles) }\end{array}$ \\
\hline A & 41.7 & 47.2 & 0.361 & 27.9 & 273.0 \\
B & 29.7 & 36.3 & 0.400 & 27.3 & 216.1 \\
C & 38.8 & 49.8 & 0.259 & 27.9 & 86.4 \\
\hline
\end{tabular}




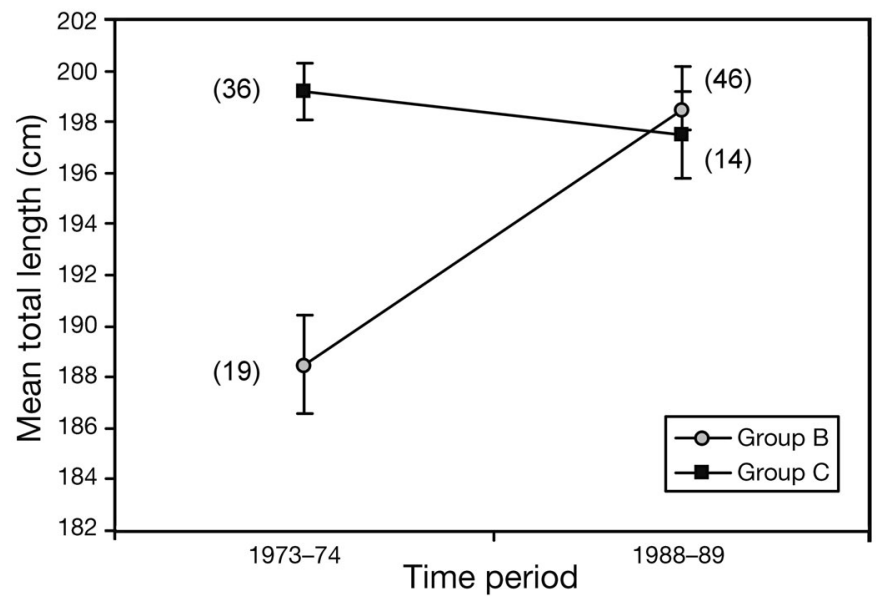

Fig. 5. Delphinus delphis. Interaction plot of mean body length with time period and group membership. Numbers in parentheses indicate sample size; error bars represent standard error of the mean

\section{DISCUSSION}

\section{A priori groups}

Stratifying data by habitat using oceanographic variables in a PCA and $k$-means cluster analysis provided the framework for spatial comparisons based on habitat. The application could easily be extended for comparing genetic, morphometric, and life history characteristics of other marine species that inhabit diverse oceanographic regions. This method could be used for developing a priori groups for developing potential stock designations if animals occur in oceanographic regions that could effectively limit animal movement. Alternatively, it could be used for developing finer scale strata for examining clinal differences by increasing the number of groups specified in the $k$-means cluster analysis.
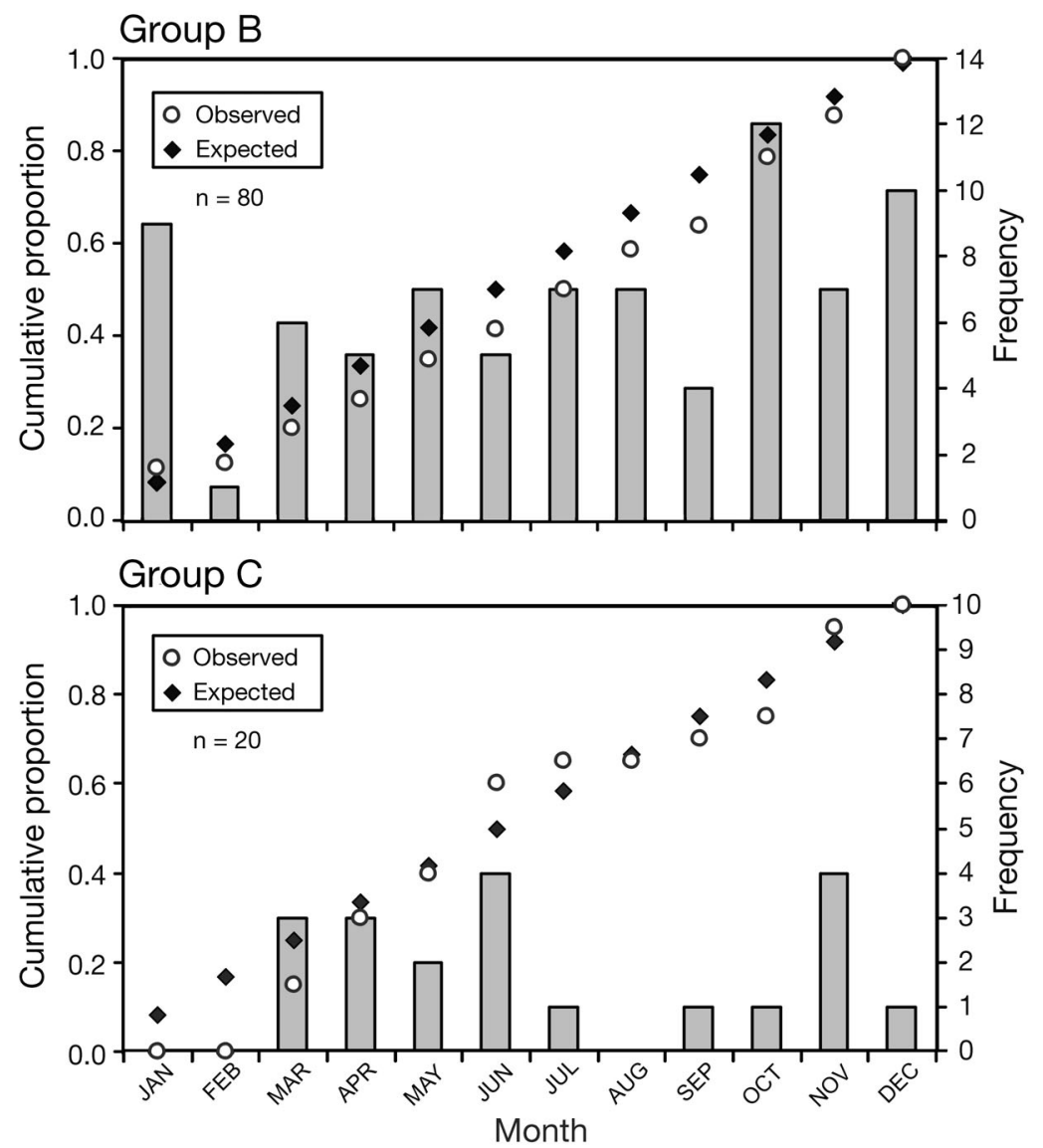

Fig. 6. Delphinus delphis. Back-projected birth date distributions for Groups B and C. Cumulative back-projected birth date distributions are not significantly different from a uniform cumulative distribution for Groups B and C. Bars indicate frequency of birth dates; points indicate observed and expected cumulative proportions

\section{Spatial and temporal comparisons}

We were not able to resolve why mean body length was significantly different for sexually mature females between years in Group B and not in Group C. However, 3 hypotheses could explain the differences: (1) movement of animals due to environmental changes, (2) morphological change in response to environmental changes, and (3) sampling biases.

Hypothesis 1: Movement of animals due to environmental change

Regime shift. Although Groups B and C could be distinct subpopulations within central Delphinus delphis, the apparent increase in length over time of Group B may be due to movement of the longer Group $\mathrm{C}$ animals into their habitat. In fact, a decrease in the abundance of the northern stock of $D$. delphis in the ETP and a concomitant increase off southern California, starting in the late 1970s, suggests a large-scale shift in the distribution of D. delphis may have occurred in the eastern North Pacific (Anganuzzi \& Buckland 1994). During the time of this hypothesized shift in distribution, a cool to warm oceanographic regime shift occurred in the North Pacific during the winter of 1976-1977. These changes were also apparent, although to a lesser degree, in the warm pool area of the ETP, where central $D$. delphis occur (Fiedler 2002b). This regime shift could have prompted a shift in distribu- 

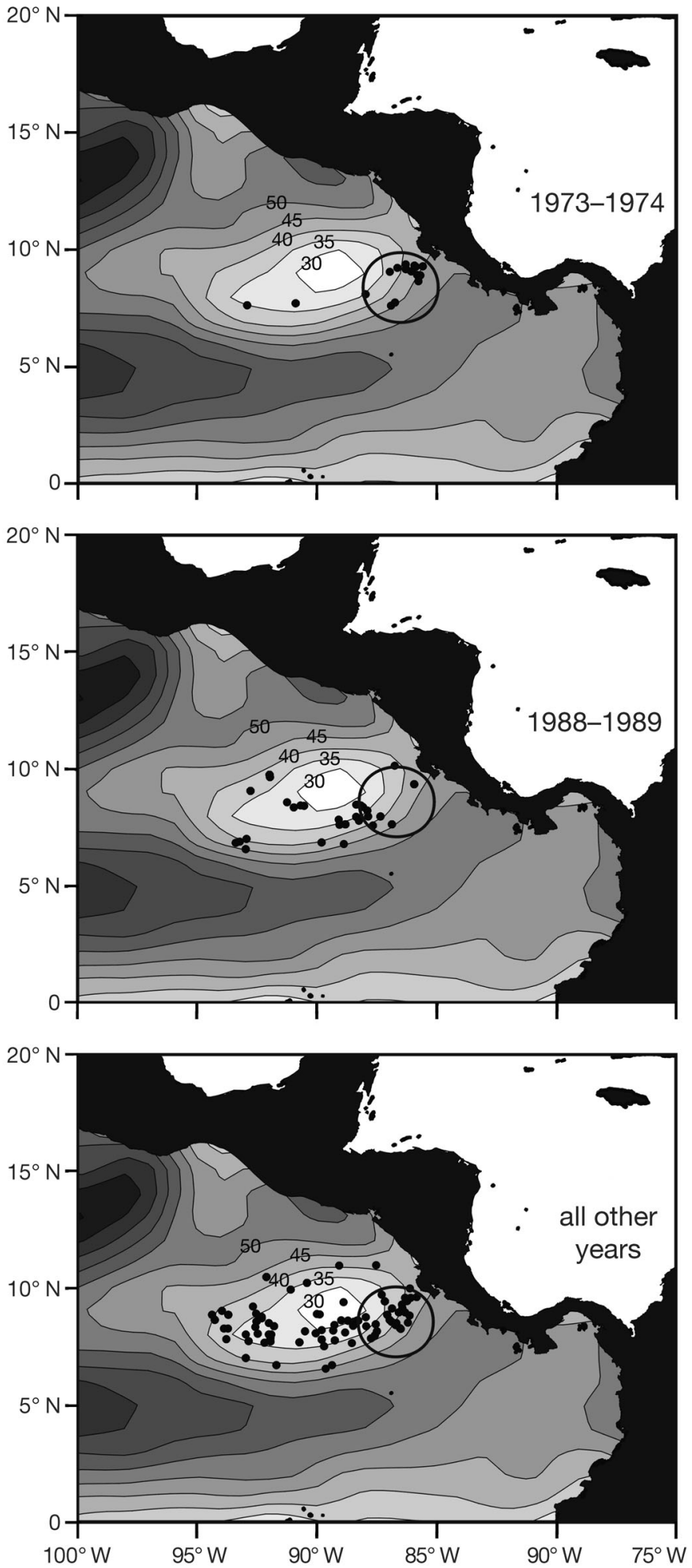

Fig. 7. Delphinus delphis. Sampling locations of Group B females by time period. The circle indicates clumping of samples in the 'early' years (top), low number of samples in this same location in the 'later' years (middle), and location of southeast samples compared to all other samples for body length for all other years in the dataset (bottom). Contours represent $20^{\circ} \mathrm{C}$ isotherm depth (m) as in Fig. 4 tion of D. delphis within the region. Either Group C animals replaced Group B as these animals moved elsewhere, or Group C animals mixed with Group B, changing the average characteristics of animals inhabiting the area.

El Niño-Southern Oscillation (ENSO). Another possibility is that sampling in the early years captured a temporary distributional shift within the ETP of shorter animals from the northern $(\bar{X}=178.5 ; 179.2 \mathrm{~cm}$; (Perrin et al. 1985, Perryman \& Lynn 1993) or southern $(\bar{x}=$ 188.5; 184.3 cm; (Perrin et al. 1985, Perryman \& Lynn 1993) stocks in response to the 1972-1973 El Niño. This is a reasonable hypothesis because Delphinus delphis have been documented to shift their distribution interannually in response to ENSO events in California (Benson et al. 2002) and ETP (Reilly \& Fiedler 1994) ecosystems. In the ETP, a shift during warm ENSO events likely occurs due to warm surface waters and deep thermoclines (Fiedler 2002b) that reduce the habitat quality for $D$. delphis. This hypothesis implies that Groups B and C were not different in mean body length and that the observed difference may be an artifact of sampling different $D$. delphis stocks during El Niño. The relative distance between Group B and the southern D. delphis stock is less than that between Group B and the northern stock (Fig. 1), suggesting that movement of southern rather than the northern stock animals into central stock habitat may be more likely.

Approximately $240 \mathrm{n}$ miles separate the southern Delphinus delphis stock and Group B within central $D$. delphis, which is not a great distance for these animals to travel. A radio-tagged D. delphis in the northeastern Pacific was documented to travel $270 \mathrm{n}$ miles from its capture site (Evans 1975) and even greater movements have been documented for this species in the ETP. Specifically, Reilly \& Fiedler (1994) reported that southern $D$. delphis only occurred in the far east off South America during the El Niño of 1987, whereas in La Niña conditions their range extended out to $110^{\circ} \mathrm{W}$. If 'far east' is assumed to be $85^{\circ} \mathrm{W}$, then the distance that animals may have traveled between these distributions is roughly $1500 \mathrm{n}$ miles. Using thermocline depth as an index of $D$. delphis upwelling habitat, during ENSO, conditions change very little at the CRD and off the coast of South America, whereas D. delphis habitat quality overall is reduced (shoaling of the thermocline) to the north and southwest of the CRD (Fig. 8). Thus, it is quite likely that individuals from the northern or southern stocks of $D$. delphis might travel to the area of the CRD in search of favorable and more stable conditions during ENSO.

However, movement of southern rather than northern stock Delphinus delphis may be more likely because the habitat of southern stock D. delphis and Group B are more comparable. Southern stock 


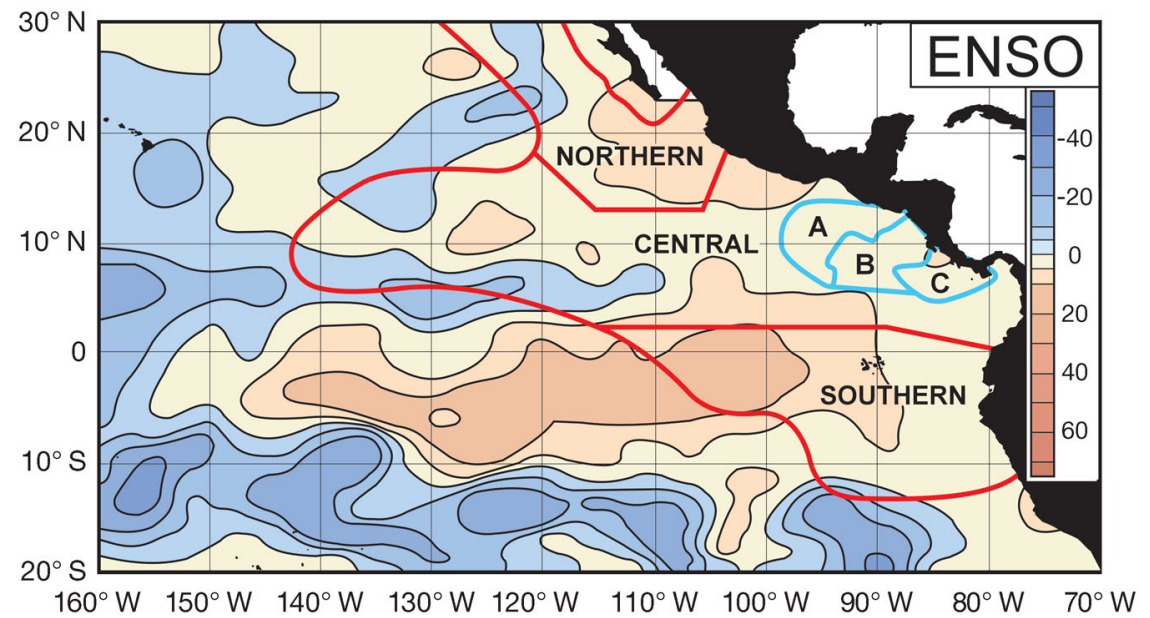

Fig. 8. ENSO effect (data spans years 1950-2003) on thermocline depth $(-2 \times$ linear fit to Southern Oscillation Index). Orange and blue shaded areas indicate deepening and shoaling of the thermocline, respectively. Base figure taken from Fiedler \& Talley (2006). Red and blue overlay lines represent

Delphinus delphis stock boundaries and habitat boundaries, respectively

affect the length animals grow to and these differences may accumulate over dolphin generations. But, why would Group C and not Group B change? The only explanation for this would be if the habitat occupied by Group B changed and that of Group $\mathrm{C}$ did not. However, we could not test this hypothesis because spatial and seasonal sampling differences in the oceanographic data available precluded analysis of an appropriate scale.

\section{Hypothesis 3: Sampling biases}

Potential sampling biases associated with dolphin by-catch in the tuna purseseine fishery in the ETP have been discussed in several papers (Perrin et al. 1976, Barlow 1985, Perrin et al. 1985, Chivers \& Myrick 1993, Archer et al.

D. delphis inhabit an area largely defined (during non-ENSO years) by a high habitat quality index comparable to that of Group B, whereas only a relatively small portion of the northern stock habitat has a high index number (Fiedler \& Reilly 1994). Thus, when southern stock $D$. delphis habitat quality is diminished during ENSO, these animals may be more likely to travel to area B where the habitat quality index likely remains high and is therefore comparable to the area they normally inhabit. Although area $\mathrm{C}$ changes very little during ENSO (Fig. 8), southern stock animals would be less likely to travel here because the habitat quality index is lower (Fiedler \& Reilly 1994) and therefore not comparable to the habitat they are accustomed to. Group A and C likely remain in their respective habitats since these areas change little during ENSO (Fig. 8) and they are likely adapted to the lower quality habitat found there.

Hypothesis 2: Morphological change in response to environmental change

Alternatively, the observed change in mean body length in Group B may be due to a change in habitat that caused a change in the availability and composition of prey species. To hypothesize that mean body length changed during such a short time period as the 1972-1973 El Niño seems biologically implausible. However, a change in mean body length over time, in response to a regime shift, may be plausible because an overall change in habitat quality may
2001). Two potential biases that were not removed through data stratification and their relation to this study will be discussed here: age structure and number of dolphins killed per set.

Perrin et al. (1985) addressed the possibility that differences in body length may be biased by differences in age structure (i.e. sampling young mature females would result in smaller mean lengths), but the mean age of mature females was constant among groups and time periods examined in this study. Therefore, we concluded that this was not a likely source of bias influencing the results of this study. Another potential source of bias is the number of dolphins killed per set. The proportion of mature female northern Stenella attenuata was found to depend significantly on this variable (Barlow 1985). Barlow suggested that this association may be due to animals segregating by reproductive maturity and that vulnerability to high kill-per-set varies by maturity status. According to this rationale, parameters associated with only mature females would not be impacted by this bias, and therefore would not be of concern in this study.

\section{CONCLUSION}

The most likely explanation for the observed differences in mean body length over time and space is that animals are moving in response to changes in their environment. The 2 most notable environmental changes that took place during the study period were an El Niño event and an oceanographic regime shift. 
Determining which of these oceanographic events caused the observed changes is not possible because the spatial and temporal resolution of the data is inadequate for further analyses.

However, there is more circumstantial evidence available to support the ENSO hypothesis driving animal movements than the regime shift hypothesis. Long term changes in the ETP oceanographic conditions resulting from the regime shift were less significant than the changes typically associated with ENSO variability (Fiedler 2002b), and relatively short-term, large-scale movements of Delphinus delphis have been documented in response to ENSO events in the California (Benson et al. 2002) and ETP (Reilly \& Fiedler 1994) ecosystems.

Estimation of life history parameters for central Delphinus delphis could be biased by the inadvertent inclusion of animals from the northern or southern stocks for some years. Although removal of samples collected during ENSO years could limit this potential bias, anomaly strength varies and the cue that triggers if and when animals move is unknown. Our analyses included only $1 \mathrm{El}$ Niño event that had a sea surface temperature anomaly index just over 2 (Fiedler 2002b), which is considered a strong event. Additionally, our results suggest that when animals move, they may stay at least a year past the end of an El Niño event (i.e. 1974 was the non-El Niño year following the 1972-1973 ENSO event). This would not be surprising, because the influence of El Niño events has been documented to influence habitat characteristics for many years beyond the event. For example, zooplankton biomass was reduced and remained reduced along the coast of Peru through the mid 1970s following the 1972-1973 El Niño (Carrasco \& Lozano 1989). The lack of knowledge and understanding about the timing of animal movement in response to ENSO events makes data stratification difficult. However, we recommend future life history analyses of $D$. delphis stratify data to consider the influence of ENSO events. Furthermore, we recommend that the fluid nature of stock boundaries particularly in ecosystems characterized by environmental events that significantly change habitat characteristics be considered in the development and implementation of management plans and all biological analyses describing animal characteristics.

Acknowledgements. The authors thank the fishery observers who collected data in the field and R. Miller and colleagues for processing the data, F. Archer for a priori 'think tanking', P. Fiedler for providing oceanographic data, K. Robertson and M. Henshaw for tooth aging, R. Cosgrove for ArcGIS support, and R. Allen for graphic support. H. I. Ellis, W. F. Perrin, and B. J. Ripley provided analytical suggestions and editorial comments.

\section{LITERATURE CITED}

Anganuzzi AA, Buckland S (1994) Relative abundance of dolphins associated with tuna in the eastern Pacific Ocean: Analysis of 1992 data. Rep Int Whal Comm 44: 361-366

Archer F, Gerrodette T, Dizon A, Abella K, Southern S (2001) Unobserved kill of nursing dolphin calves in a tuna purseseine fishery. Mar Mamm Sci 17:540-554

Barlow J (1985) Variability, trends, and biases in reproductive rates of spotted dolphins, Stenella attenuata. Fish Bull 83: $657-669$

Batschelet E (1965) Statistical methods for the analysis of problems in animal orientation and certain biological rhythms. Am Inst Biol Sci, Monograph, Washington

Benson SR, Croll DA, Marinovic BB, Chavez FP, Harvey JT (2002) Changes in the cetacean assemblage of a coastal upwelling ecosystem during El Niño 1997-98 and La Niña 1999. Progr Oceanogr 54:279-291

Carrasco S, Lozano O (1989) Seasonal and long-term variations of zooplankton volumes in the Peruvian Sea, 1964-1987. In: Pauly D, Muck P, Mendo J, Tsukayama I (eds) The Peruvian upwelling system: dynamics and interactions. ICLARM, Manila, p 82-85

Chivers SJ, DeMaster DP (1994) Evaluation of biological indices for 3 eastern Pacific dolphin species. J Wildl Manag 58:470-478

Chivers SJ, Myrick AC Jr (1993) Comparison of age at sexual maturity and other reproductive parameters for 2 stocks of spotted dolphin, Stenella attenuata. Fish Bull 91:611-618

Danil K (2004) Growth and reproduction of female shortbeaked common dolphins, Delphinus delphis, in the eastern tropical Pacific. MS thesis, University of San Diego, CA

Dizon AE, Perrin WF, Akin PA (1994) Stocks of dolphins (Stenella spp. and Delphinus delphis) in the eastern tropical Pacific: a phylogeographic classification. NOAA Tech Rep NMFS 119, US Dept of Commerce

Douglas ME, Schnell GD, Hough DJ (1984) Differentiation between inshore and offshore spotted dolphins in the eastern tropical Pacific Ocean. J Mammal 65:375-387

Evans WE (1975) Distribution, differentiation of populations, and other aspects of the natural history of Delphinus delphis Linnaeus in the northeastern Pacific. PhD thesis, University of California at Los Angeles

Fiedler PC (2002a) The annual cycle and biological effects of the Costa Rica Dome. Deep-Sea Res I 49:321-338

Fiedler PC (2002b) Environmental change in the eastern tropical Pacific Ocean: review of ENSO and decadal variability. Mar Ecol Prog Ser 244:265-283

Fiedler PC, Reilly SB (1994) Interannual variability of dolphin habitats in the eastern tropical Pacific: effects on abundance estimated from tuna vessel sightings, 1975-1990. Fish Bull 92:451-463

Fiedler PC, Talley LD (2006) Hydrography of the eastern tropical Pacific: a review. Prog Oceanogr 69:143-180

Geffen E, Anderson MJ, Wayne RK (2004) Climate and habitat barriers to dispersal in the highly mobile grey wolf. Mol Ecol 13:2481-2490

Hansen DV, Herman A (1988) A seasonal isotherm depth climatology for the eastern tropical Pacific. NOAA Tech Rep ERL-434-AOML 33, US Dept of Commerce

Hohn AA, Hammond PS (1985) Early postnatal growth of the spotted dolphin, Stenella attenuata, in the offshore eastern tropical Pacific. Fish Bull 83:553-566

Hohn AA, Scott MD, Wells RS, Sweeney JC, Irvine AB (1989) Growth layers in teeth from known-age, free-ranging 
bottlenose dolphins. Mar Mamm Sci 5:315-342

Kessler WS (1990) Observations of long rossby waves in the northern tropical Pacific. J Geophys Res 95 (C4): $5183-5217$

McRae BH, Beier P, Dewald LE, Huynh LY, Keim P (2005) Habitat barriers limit gene flow and illuminate historical events in a wide-ranging carnivore, the American puma. Mol Ecol 14:1965-1977

Myrick AC Jr, Hohn AA, Sloan P, Kimura M, Stanley D (1983) Estimating age of spotted and spinner dolphins (Stenella attenuata and Stenella longirostris) from teeth. NOAA Tech Memo NMFS-SWFC-30, US Dept of Commerce

Natoli A, Birkun A, Aguilar A, Lopez A, Hoelzel AR (2005) Habitat structure and the dispersal of male and female bottlenose dolphins (Tursiops truncatus). Proc R Soc Biol Sci Ser B 272:1217-1226

Norris KS (1961) Standardized methods for measuring and recording data on the smaller cetaceans. J Mammal 42: 471-476

Perrin WF, Coe JM, Zweifel JR (1976) Growth and reproduction of the spotted porpoise, Stenella attenuata, in the offshore eastern tropical Pacific. Fish Bull 74:229-269

Perrin WF, Scott MD, Walker GJ, Cass VL (1985) Review of

Editorial responsibility: Otto Kinne (Editor-in-Chief), Oldendorf/Luhe, Germany geographical stocks of tropical dolphins (Stenella spp. and Delphinus delphis) in the eastern Pacific. NOAA Tech Rep NMFS 28, US Dept of Commerce

Perryman WL, Lynn MS (1993) Identification of geographic forms of common dolphin (Delphinus delphis) from aerial photographs. Mar Mamm Sci 9:119-137

Reilly SB (1990) Seasonal changes in distribution and habitat differences among dolphins in the eastern tropical Pacific. Mar Ecol Prog Ser 66:1-11

Reilly SB, Fiedler PC (1994) Interannual variability of dolphin habitats in the eastern tropical Pacific. I: Research vessel surveys, 1986-1990. Fish Bull 92:434-450

Reilly SB, Fiedler PC, Gerrodette T, Ballance LT, Pitman RL, Borberg JM, Holland RC (2002) Eastern tropical Pacific dolphin habitats-interannual variability 1986-2000. Admin Rep LJ-02-21, Southwest Fisheries Science Center, La Jolla, CA

Tabachnik BG, Fidell LS (1989) Using multivariate statistics. Harper \& Row, New York

Walker WA (1981) Geographical variation in morphology and biology of bottlenose dolphins (Tursiops) in the eastern North Pacific. Admin Rep LJ-81-03C, Southwest Fisheries Science Center, La Jolla, CA

Submitted: June 21, 2005; Accepted: January 10, 2006 Proofs received from author(s): July 17, 2006 